\title{
Antidepressants and psychological treatment: Hard reasons for synergy
}

\author{
Daniel M. Campagne \\ Universidad Nacional de Educación a Distancia, Madrid, España
}

\begin{abstract}
Improving the efficacy of depression treatment is a clinical necessity. «Synergy» is the systematic process in which different treatments of and approaches to mood disorders are evaluated and made to work coherently to optimize their results. Depression treatment has shown to benefit from the synergy of pharmacological and psychological processes. Our aim was to evaluate present evidence as to synergizing psychological therapy and pharmacotherapy in mood disorders, reflecting the related brain systems and circulating biological substances. Multiple brain regions are involved in mood disorders, resulting in multiple-target effects of substances, each influencing neurobiological balance, and depending on individual aspects. Large studies showed that psychological treatment may, overall, be more effective than medication. However, the synergy of both provided significantly increased effects that were largely independent of each other, and each added about $50 \%$ to the overall effects of combined treatment. Identified neuropsychobiological pathways were found, as well as appreciable evidence that, in depression, the synergy of both treatments can be expected to produce better results through reciprocal effects in cortical, subcortical and visceral systems. In compromised situations such as pregnancy and adolescence, psychological treatments for mood disorders may have preference over drug treatment, but synergy remains essential.
\end{abstract}

Keywords: Depression; mood disorders; neurobiology; pharmacotherapy; psychological treatment; synergy

\section{Antidepresivos y tratamiento psicológico: Razones contundentes para la sinergia}

Resumen: Mejorar la eficacia del tratamiento de la depresión es una necesidad clínica. «Sinergia» es el procedimiento sistemático que evalúa y hace funcionar coherentemente tratamientos y/o enfoques sobre trastornos de ánimo diferentes para optimizar los resultados. El tratamiento de la depresión ha demostrado beneficiarse de la sinergia de procedimientos farmacológicos y psicológicos. Nuestra meta era evaluar la evidencia existente en cuanto sinergias entre la terapia psicológica y la farmacoterapia en los trastornos de ánimo, reflejando los sistemas cerebrales y las sustancias biológicas circulantes. Trastornos de ánimo involucran múltiples regiones del cerebro, resultando en efectos de los fármacos sobre múltiples metas, cada una influyendo el equilibrio neurobiológico, dependiendo de los aspectos individuales. Amplios estudios demuestran que, generalmente, el tratamiento psicológico puede ser más eficaz que los antidepresivos. Sin embargo, la sinergia de ambos produjo efectos significativamente mayores y en gran medida independientes, aportando ambos aproximadamente un $50 \%$ a 10 s efectos totales del tratamiento combinado. Encontramos vías sinérgicas neuropsicobiológicas identificadas. Consta evidencia apreciable que, en depresión, es de esperar que la sinergia de ambos tipos de tratamientos produzca mejores resultados por sus efectos recíprocos en sistemas corticales, subcorticales y viscerales. En situaciones comprometidas, tales como el embarazo y la adolescencia, los tratamientos psicológicos de los trastornos de ánimo pueden merecer preferencia sobre el tratamiento con fármacos, pero sinergia sigue siendo esencial.

Palabras clave: Depresión; trastornos del estado de ánimo; neurobiología; farmacoterapia; tratamiento psicológico; sinergia

Recibido: 09 de octubre 2020: aceptado: 10 de febrero 2021

Correspondencia: Daniel M. Campagne, Universidad Nacional de Educación a Distancia, Facultad de Psicología, Juan del Rosal 10, 28040 Madrid, España. Correo-e: danplaton@hotmail.com. Tel.: +34 965873120

\section{Introduction}

Present pharmacological treatment of mood disorders with antidepressants and anxiolytics 
is primarily and routinely directed at modifying levels of specific mood-related substances and has predominantly corticolimbic effects (Messina, Sambin, Palmieri, and Viviani, 2013). Thus, a prime effect is facilitating functionality. However, a brain thus treated with psychoactive substances may be functional but has not regained previous «normality». Opinions and study results differ as to which antidepressant is most effective and rankings not necessarily contemplate side effects (Cipriani et al, 2018). Differently, psychological treatment of mood disorders results in lasting psychobiological normality. Synergy, as the intended and structured application of both pharmacological and psychological treatment, as required, aims at comprehensive results, short and long-term. It may be considered a form of transdiagnostics (Sandín et al, 2012). Synergistic approach has a neurobiological basis. Synergy has been recognized as an essential component of modern psychiatry (Nasrallah, 2006). Nevertheless, heralded advances in depression treatment are typically limited to pharmacotherapy or biological methods, obviating proven psychological approaches (Licinio \& Wong, 2020)

Still, at present, clinical treatment of mood disorders either centers on psychological treatments or favors pharmacological remedies that are incidentally supported by psychological treatment. Each proved measurably and comparably effective but they differ in long term results and in side effects. One cause for differences lies in their different loci of action. The heterogenic interrelation between mental states and physiological parameters has become clearer (Gevins et al., 2002, Wilkinson et al., 2019). Some 1500 identified different combinations of behavioral and neurobiological symptoms for major depressive disorder alone result in a need for markedly different treatment approaches (Sharpley and Bitsika, 2013).

In our context, synergy is the systematic process evaluating different treatment options or agents and their intended simultaneous application aimed at enhancing their cumulative function and effects. This implies optimizing combinations of treatments individually, including lifestyle changes. Synergy is therefore more than adding «other» treatment elements on a chance of adding value. In mood disorders, synergy may improve the comparable efficacy of antidepressants and psychotherapy, hence mental health services worldwide are developing more synergy (Ellis et al., 2017; Hannigan et al., 2018). Increasing intercare collaboration, although not yet the same as collaborative care, was found to favor efficiency, care quality and adequate professional training, but synergy goes further.
Synergy: principal observations

Clinical treatment dilemmas are frequent in mood disorders. The existing divergence of treatment propositions for mood disorders also differently prepares medical and psychology professionals. Research results are ambivalent because, in mood pathology studies and depending on design and patient characteristics, either pharmacological treatment or psychological treatment resulted more effective. In depression, combining treatments favored results. A timid consensus is forming that both therapeutic approaches should be coordinated from inception to warrant more positive results in the long term (Cuijpers et al., 2014; Roiser, 2015; Seeberg et al., 2018; Davidson, 2010). However, insufficiently unified criteria complicate combination protocols.

In combined treatment application, timing of intervention elements is of importance. An optimal protocol requires previous diagnoses integrating neurobiology, psychiatry and psychology, considering clinical availability, cost and patient characteristics. The physician may consider pharmacology and not psychotherapy. In turn, psychologists may find psychological treatments a better fit.

Health authorities and organizations are aware of this problem but consensus on the necessary bridging strategies is still lacking. Moreover, availability or cost of psychological treatment may be obstacles, although less costly internet-assisted protocols show positive results (Thase et al., 2018, Cuijpers et al., 2019), also in primary care (Høifødt et al., 2013).

The Lancet Psychiatry Commission affirmed in 2018: "The combination of psychological and pharmacological treatments needs to be better understood, both in terms of the clinical effect and the underlying shared and different mechanisms» (Holmes et al., 2018). However, said statement surprisingly purports that the goal of adding psychotherapy to pharmacotherapy should be «remov(ing) a barrier to successful treatment with an antidepressant drug», whereas a primary goal of mood disorder treatment should be treating depression without creating any (antidepressant-) dependency (Moncrieff, 2016). Also, the statement classifies psychotherapy as a mere auxiliary to antidepressants which disregards synergy's - demonstrated - axiom that treatments are of equal value (Kappelmann et al, 2020). Authoritative comparisons admit that psychological treatment may, overall, be more effective than medication: $54 \%$ improved with antidepressants, $62 \%$ with psychological treatment (Cuijpers, Stringaris \& Wolpert, 2020). 


\section{Neurological balance and mood disorders}

Causes and consequences of mood disorders always combine biological and psychological elements. Treatments limited to pharmacology reflect a materialism wrongly presupposing mental events to be reducible to biological (brain) events. Behavioral neuroscience or psychobiology, and especially psychoneuroimmunology, provide clinical data as to optimal system interactions requiring combined treatments. In clinical practice, psychiatry and psychology are not yet at synergy, however, although neuroscience brings increasingly solid data in favor of their greater synergy. Neurobiological pathways and mechanisms in any mood disorder are never unique or linear. Substances involved, sites of action, and repercussions in other neuronal events are complex but knowable (Sharpley and Bitsika, 2013).

Psychological and biological components of a mental disorder alter neurochemical balance by diverse mechanisms. Implicated neurotransmitters are monoamines, gamma-aminobutyric acid (GABA) and glutamate, but also many other modulators including adenosine, cannabinoids, neuropeptides, hormones, neurotrophins, nitric oxide, cytokines and different cellular modulators. Genetics do play a role (Liu et al., 2018). All biological and psychological reactions are measurably manifest in different brain structures. In anxiety or depression, antidepressants reduced activity in the right paracingulate region whilst psychotherapy did the opposite and increased activity, interpreted as a topdown intent to correct the abnormal corticolimbic brain activity caused by the disorder (Kalsi et al., 2017). Also, functional magnetic resonance imaging (fMRI) showed that pain is expressed in the same place of the brain irrespective of its origin in a physical or a psychological event (Eisenberger, 2012). Thus, the brain does not functionally distinguish between noxious stimuli of biological or psychological origin. Subjects could be trained to mentally re-categorize sensations, for instance to reframe pain as a pleasant experience, independently of the opioid system, and clinical use of psychological mental imagery techniques for re-categorizing symptoms has been found clinically effective (Berna et al., 2018). Stress is another example of this bifocality. Diverse neurological alterations provoked by stress are identified both in animal and human models and impact on virtually all systems: motor, sensorial, endocrine, immune, cardiovascular, neural, and psychological (Kumar et al., 2013).

The psychological significance of interventions that mitigate non-emotional symptoms of anxious states such as chronic pain, cardiovascular conditions and a variety of somatic complaints is a given (Millan, 2003). Brain circuits relevant for both emotional and cognitive components of depression and anxiety are especially relevant. Several limbic and cortical structures are involved in mood and mnesic mechanisms (Gray, 1987). Apart from the limbic system - predominantly the amygdala, hippocampus and the periaqueductal grey - the stress response and its control receive significant though sometimes counterposed contributions from nearly all cortical regions (insular, orbital, entorhinal, temporal, associative, frontal, pre-frontal, cingulate, parietal and visual) (Groenewegen and Uylings, 2000,Pralong et al., 2002; Hurley et al., 1991). One consequence of this multiinput is significant inter-individual differences of clinical relevance. For example, $80 \%$ of depressed persons show elevated cortisol (Thompson and Craighead, 2008) but $20 \%$ do not, thus hypothalamic-pituitary-adrenal (HPA) hyperresponsivity is not universal among depressed patients. In short, multiple regions are involved in mood disorders, resulting in multiple-target effects of substances, each influencing neurobiological balance (Hindmarch, 2001).

Emotion and cognitive processes are confirmed to have a different basis, emerging from systems that generate an «instinctive» action from visceral homeostatic interoceptors, predominantly in subcortical regions (Panksepp, 2003). These large but slow-acting systems generate the «intentions during the action» and generate «raw» affective states independent of cognitive mechanisms (Searle, 1983). On the other hand, cognitive processes relate to sensorial exteroceptive systems, with mechanisms of fast neuronal action with little intrinsic affective content that produce the «intentions of the action» (Heyes and Dickinson, 1990). They generate affective sentiments in specific subcortical circuits where slow-triggered neural systems proliferate with an ample presence of neuropeptides, widespread in the visceral nervous system (Panksepp, 1993, 2010). Emotional responses probably surge from medial limbic regions of the neuroaxis. Thus, emotional processes relate more with viscera-neuropeptide systems than with somatic functions of the brain and rapid-rate Magnetic Transcranial Stimulation (rTMS) - an alternative therapy with strong indirect effects on subcortical processes - emerged as a non-invasive intervention for depression (Teng et al., 2017; Mishra et al., 2011; Berlim et al., 2013), and possibly for stress (Hedges et al., 2003). Thus, mood disorders implicate multiple regions, multiple substances and multiple targets but, moreover, the emotional and cognitive brain processes involved are essentially different, a fact that treatment should target. 
Inherent limits on the effects of psychoactive medication

Cognitive system research is producing new data on the scope of linear action drugs, widely used in mood disorders. As said, neurotransmitters and receptors may mediate opposite actions depending on their place in different brain structures; of their pre- or postsynaptic presence; the duration of their activation; and the type of mood disorder involved. However, different neuromodulators may have a similar influence on mood states as the result of synergous action in multiple loci. For example, substances that reinforce GABAergic transmission in the amygdala reduce anxiety, whilst exciting neurons that contain corticotrophin liberating factor (CRF) have the opposite anxiogenic effect (Zeng et al., 2003). Surprisingly, improving the liberation of serotonin (5-HT), noradrenalin (NA) or dopamine (DA) proved not to be synonymous of an anxiolytic consequence, nor does its reduction warrant anxiogenic consequences (Millan, 2003). Anxiolytic and anxiogenic consequences are therefore independent of the circulating quantity of said monoamines. Notwithstanding these uncertainties, manipulating their release is still the essence of antidepressant treatment, (Joca et al., 2015).

When evaluating the efficacy of therapy, we need to integrate essential concepts:

(1) Neurotransmitters and other modulators present high levels of co-storage and co-liberation and operate in a coordinated and dependent way (Jing et al., 2001; Blank, Nijholt, Vollstaedt, et al., 2003; Blank, Nijholt, Grammatopoulos, et al., 2003; Hnasko and Edwards, 2012; Merighi, 2018). At the synaptic level of specific neurons, multiple transmitters and receptors interact (cross talk). Interrelated receptors not only interact with intracellular messengers but physically associate to form heterodimers with functional properties that differ from their homomers. In laboratory cultures, the assembly of functional heterodimeric adrenergic, serotonergic, dopaminergic, opioid, and adenosinergic receptors has been observed (Maggio et al., 1993; Pan et al., 2002). Heterodimeric structures in the brain and their cross talk are common for serotonin and glutamate (Wischhof and Koch, 2016, Halberstadt et al., 2019) and opioids (Fujita et al., 2015).

(2) The activation of a specific receptor does not always produce the same effect. Certain antidepressant drugs may favor the activation of one in many different alternative intracellular «cascades», whilst coupled to the same receptor. These cascades may have different associations of beneficial properties and adverse effects (Kenakin, 2002; Hunyady et al., 2003). Cascades from certain natural antidepressants such as hyperforin have also been observed (Bouron and Lorrain, 2014).

(3) Any linear actuation of drugs may be nullified by «constitutionally active» receptors: those that show spontaneous linking to $\mathrm{G}$ proteins (Millan et al., 1999). These receptors act as «inverted agonists,» annulling the activity of agonists although the effects of both may be blocked again by «neutral» antagonists (Seifert and Wenzel-Seifert, 2002). With heterologous receptors - those activated by more than one substance - the activation of inverse agonists may be more efficacious than the use of neutral antagonists. Animal studies confirm the effects of inverse agonists on depression and brain substance homeostasis (Iida et al., 2017).

These data transmit an important message to the clinician. Given the intimate, complex and reciprocal interactions between biological parameters and mood states as integrated and modulated in structures such as the amygdala, the hippocampus and the cortex (McKe11-Carter et al., 2003), it is improbable that any pharmacological substance could influence mood profoundly and foreseeably over the long turn. However, psychological mechanisms will influence both mood and biological factors.

\section{Interactions and multiple controls}

This amalgam of counterposed cortical, limbic and subcortical influences makes regulation and stability of clinically manifest functionality depend on a hierarchy of controls. Substances that alter mood also influence cognition, motor behavior, nociception, endocrine secretion, and emotion. Mood modulation may only be a secondary effect. This intracellular phenomenon of «exaptation» exists in receptors, neurotransmitters, neurons and brain circuits and may constitute the evolutionary foundation of the central nervous system.

All brain modulators interact, and their functional properties reflect over time and space. At most, the individual components of mood state networks may disclose a partial explanation of underlying mechanisms. The multiplicity of endogenous mechanisms of mood changes indicates that lasting therapeutic efficacy of drugs interacting with just one mechanism is questionable. Agents affecting two or more mechanisms should have a better therapeutic efficacy, for example those that reinforce endogenous anxiolytic mechanisms whilst inhibi- 
ting anxiogenic factors. However, therapeutic targets that combine corticolimbic and subcortical mechanisms may obtain better and lasting results. Psychological treatments showed to influence more substances than antidepressant monoamines, consequently:

(1) Affective-emotional states relate to cortical neurotransmitters but also to other substances with cortical, subcortical and visceral action, with multiple interrelated consequences, yet to be completely identified and understood.

(2) These substances respond to balancing mechanisms of a biological and of a psychological nature, each often requiring holistic adjustment.

\section{Autonomous value of psychological treatment in mood disorders}

The aforementioned mechanisms indicate that the treatment of mood disorders exclusively with psychoactive medication has inherent limitations.

Re-establishing mood-related normality implicates multiple substances and structures, as indicated above. This goal is not likely to be obtained with drugs acting on one or two neurotransmitters (Ressler and Nemeroff, 2000), nor is a brain on antidepressants the same as a brain without depression (Willner et al., 2013), hence the need for synergistic approaches. Systematic synergy between psychological treatment and drug treatment does not mean that drugs must always be used, but that both aspects need always be evaluated, and psychological treatment always accompany. In recent decades, specific psychological therapies proved more efficacious. The response of selected neurotransmitters to psychological treatment was less solid than obtained with specific antidepressants, but a definable positive correlation was established (Van der Pompe et al., 2001; Niemeier et al., 1999; Karlsson et al., 2010).

A positive neurobiological impact of psychological treatment on serotonin or the glucose metabolism was established (Karlsson et al., 2010; Kennedy et al., 2007) Functional and rest MRI, but also newer voxel-based positron emission tomography (PET) identified brain regions affected by depression and showed the changes in active substances as a result of therapy (Linden, 2006). All studies underline a notorious individual variety as to affected areas (Diener et al., 2012; Müller et al., 2017).

As said, pharmacotherapy may facilitate functionality without re-establishing overall normality, as it modifies the manifestations of neurochemical imbalance of the disorder (bottom-up), requiring prolonged treatment to reduce the risk of relapse. Even then, drugs do not necessarily re-establish normal or pre-disorder levels of target substances, but rather facilitate the brain's functionality whilst it attempts to regain neurobiological normality by its own means. Psychological treatments have proved to serve this last purpose. Their (topdown) effects affect many neurobiological substances. In depression, therapy measurably changed long-term levels of neurotransmitters, neurosteroids, and a plethora of other substances (Honeyman, 2016).

Clinically, concurrent and synergic application of both approaches still needs time. Antidepressants may need up to ten weeks to reach therapeutic efficacy (Trivedi et al., 2006). Psychological treatments may need a similar time, but a strong early response is obtained in a significant number of cases (Lambert, 2005) thus early initiation is recommended. The person's functionality may start to improve with antidepressants before psychological treatment commences (Petersen, 2006) although this is questioned. Psychological treatment ab initio may advance positive results by 3 to 6 weeks. Psychological treatment was found to enhance the effects of antidepressants and improve patients' long-term prognosis (Hollon et al., 2005), although with several observations. In their 2014 meta-analysis of 52 studies, $N=3,623$, Cuijpers and colleagues found that adding psychotherapy to drug therapy in depression and anxiety disorders provided «effects that were largely independent of each other, and each add about $50 \%$ to the overall effects of combined treatment» (Cuijpers et al., 2014). This moderately large effect and clinically meaningful difference in favor of combined treatment lasted for at least two years after treatment. Also in 2014, a Cochrane systematic review on children and adolescents indicated similar provisional results (Cox et al., 2014). However, we should not conclude that adding psychoactive medication is «boosting the effects and retention of psychological interventions», as the Lancet Commission affirms. Both treatment types have their reasons and mechanisms, are of equal value, and positive treatment results depend on synergetic clinical strategy.

\section{Special importance: Mood disorders in vulnerable cohorts}

Consideration is required with special cohorts such as adolescents and perinatal women. Side effects of antidepressants preoccupy and, although medication should not be excluded for specific cases, alternative treatments are to be actively preferred (Campagne, 2019).

In adolescents, but also in adults, selective serotonin reuptake inhibitor (SSRI) antidepressants, especially 
citalopram, was argued to substantially increase the risk of suicide and a Federal Drugs Administration (FDA) black-box warning was issued in 2012. Their use should be avoided when valid alternatives are available. A recent small study establishing the contrary does not yet cancel this black box warning.

\section{Conclusion}

Depression is the world's third leading cause of years lived with disability (The Lancet, 2018). Thus, the search for highest possible efficacy of treatment is a global concern.

Neuropsychobiological research confirms that mood disorders produce simultaneous, overlapping and counterposed effects in various neural systems both at corticolimbic and subcortical as well as at visceral or endocrine levels (Marwood et al., 2018). As present, pharmacological antidepressant and anxiolytic treatments predominantly aim at corticolimbic functioning, and do not aim to produce necessary subcortical or visceral adjustments. A synergic combination of pharmacotherapy and psychological treatment has more complete effects, leading to earlier remission of symptoms and regaining neurobiopsychological stability.

Importantly, biological and psychosocial factors are not dichotomous but are concurrent mechanisms, where the need for synergy of psychotherapy and pharmacotherapy is supported by different neural mechanisms, as brain imaging studies show (Dean and Keshavan, 2017; Goodwin et al., 2018; Boccia et al., 2016).

Synergy is defined to be always intentional and requires early coordination of pharmacological and psychological treatments and a therapeutic protocol contemplating both treatment approaches, requiring paradigmatic protocol changes and recognizing the relevancy of neurobiological processes underlying mood disorders. For the clinician, synergy is not just an option but an important tool. This does not mean that both treatments should always be applied together. Both aspects should be evaluated (Garland et al., 2016). However, recent quality studies and meta-analysis indicate that combined therapies are - in general significantly more effective in mood disorders (Cuijpers et al., 2020).

Research suggestions emerge from the above. Establishing the efficacy of each specific pharmacological or psychological treatment is important, but not enough (Moriana \& Martinez, 2011). The concurrent efficacy of both treatments and their neurobiological processes need further clinical definition, resulting in recommendations for synergic mood disorder evaluation protocols and treatment. Normative guidance on neurobiological factors in mood disorder treatment could unify clinical criteria.

\section{Conflicts of Interest}

The author has no conflicts of interest to declare

\section{References}

Berlim, M. T., Van den Eynde, F., \& Jeff Daskalakis, Z. (2013). Clinically meaningful efficacy and acceptability of lowfrequency repetitive transcranial magnetic stimulation (rTMS) for treating primary major depression: a meta-analysis of randomized, double-blind and sham-controlled trials. Neuropsychopharmacology 38(4):543-551. https://doi.org/10. 1038/npp.2012.237.

Berna, C., Leknes, S., Ahmad, A. H., Mhuircheartaigh, R. N., Goodwin, G. M., \& Tracey, I. (2018). Opioid-independent and opioid-mediated modes of pain modulation. Journal of Neuroscience 0854-18. https://doi.org/10.1523/JNEUROSCI. 0854-18.2018.

Blank, T., Nijholt, I., Vollstaedt, S., \& Spiess, J. (2003). The corticotropin-releasing factor receptor1 antagonist CP154,526 reverses stress-induced learning deficits in mice. Behavioural Brain Research 138, 207-213.

Blank, T., Nijholt, I., Grammatopoulos, D. K., Randeva, H. S., Hillhouse, E. W., \& Spiess, J. (2003). Corticotropin-releasing factor receptors couple to multiple G-proteins to activate diverse intracellular signaling pathways in mouse hippocampus: role in neuronal excitability and associative learning. Journal of Neuroscience 23, 700-707.

Boccia, M., Piccardi, L., \& Guariglia, P. (2016). How treatment affects the brain: meta-analysis evidence of neural substrates underpinning drug therapy and psychotherapy in major depression. Brain Imaging and Behavior 10 (2), 619-627. https://doi.org/10.1007/s11682-015-9429-x..

Bouron, A., \& Lorrain, E. (2014). Cellular and molecular effects of the antidepressant hyperforin on brain cells: Review of the literature. Encephale 40(2), 108-113. https://doi.org/10.1016/ j.encep.2013.03.004.

Campagne, D. M. (2019). Antidepressant use in pregnancy: are we closer to consensus? Archives of Womens Mental Health 22(2), 189-197. https://doi.org/10.1007/s00737-018-0906-2.

Cipriani, A., Zhou, X., Del Giovane, C., Hetrick, S. E., Qin, B., Whittington, C., ... \& Xie, P. (2016). Comparative efficacy and tolerability of antidepressants for major depressive disorder in children and adolescents: a network meta-analysis. The Lancet, 388(10047), 881-890.. https://doi.org/10.1016/S01406736(17)32802-7

Cox, G. R., Callahan, P., Churchill, R., Hunot, V., Merry, S. N., Parker, A. G., \& Hetrick, S. E. (2014). Psychological therapies versus antidepressant medication, alone and in combination for depression in children and adolescents. Cochrane Database of Systematic Reviews (11):CD008324. https://doi. org/10.1002/14651858.CD008324.pub3. 
Cuijpers, P., Stringaris, A., \& Wolpert, M. (2020) Treatment outcomes for depression: challenges and opportunities. Lancet Psychiatry (11):925-927, https://doi.org/10.1016/S22150366(20)30036-5.

Cuijpers, P., Sijbrandij, M., Koole, S. L., Andersson, G., Beekman, A. T., \& Reynolds, C.F. (2014). Adding psychotherapy to antidepressant medication in depression and anxiety disorders: a meta-analysis. World Psychiatry 13(1), 56-67. https://doi. org/10.1002/wps. 20089.

Cuijpers, P., Noma, H., Karyotaki, E., Cipriani, A., \& Furukawa, T. A. (2019) Effectiveness and Acceptability of Cognitive Behavior Therapy Delivery Formats in Adults with Depression. A Network Meta-analysis. JAMA Psychiatry 76(7):700-707. https://doi.org/10.1001/jamapsychiatry.2019.0268.

Cuijpers, P., Noma, H., Karyotaki, E., Vinkers, C. H., Cipriani, A., \& Furukawa, T. A. (2020). A network meta-analysis of the effects of psychotherapies, pharmacotherapies and their combination in the treatment of adult depression. World Psychiatry 19(1), 92-107. https://doi.org/10.1002/wps.20701.

Davidson, J. R. (2010). Major depressive disorder treatment guidelines in America and Europe. The Journal of Clinical Psychiatry 71 Suppl E1:e04. https://doi.org/10.4088/JCP. 9058se1c.04gry.

Dean, J., \& Keshavan, M. (2017). The neurobiology of depression: An integrated view. Asian Journal of Psychiatry 27, 101-111. https://doi.org/10.1016/j.ajp.2017.01.025.

Diener, C., Kuehner, C., Brusniak, W., Ubl, B., Wessa, M., \& Flor, H. (2012). A meta-analysis of neurofunctional imaging studies of emotion and cognition in major depression. Neuroimage 61(3), 677-685.https://doi.org/10.1016/j.neuroimage.2012.04. 005. Epub 2012 Apr 12.

Eisenberger, N. I. (2012). The neural bases of social pain: evidence for shared representations with physical pain. Psychosomatic Medicine 74(2), 126-135. https://doi.org/10.1097/PSY.0b013 e3182464dd1.

Ellis, L. A., Churruca, K., \& Braithwaite, J. (2017). Mental health services conceptualised as complex adaptive systems: what can be learned? International Journal of Mental Health Systems 11, 43. https://doi.org/10.1186/s13033-017-0150-6.

Fujita, W., Gomes, I., \& Devi, L. A. (2015). Heteromers of $\mu-\delta$ opioid receptors: new pharmacology and novel therapeutic possibilities. British Journal of Pharmacology 172(2):375-87. https://doi.org/10.1111/bph.12663.

Garland, E. J., Kutcher, S., Virani, A., \& Elbe, D. (2016). Update on the Use of SSRIs and SNRIs with Children and Adolescents in Clinical Practice. Journal of the Canadian Academy of Child and Adolescent Psychiatry 25(1): 4-10.

Gevins, A., Smith, M. E., \& McEvoy, L. K. (2002). Tracking the Cognitive Pharmacodynamics of Psychoactive Substances with Combinations of Behavioral and Neurophysiological Measures. Neuropsychopharmacology 26,1, 27-39. https:// doi.org/10.1016/S0893-133X(01)00300-1.

Giulietti, M., Vivenzio, V., Piva, F., Principato, G., Bellantuono, C., \& Nardi, B. (2014). How much do we know about the coupling of G-proteins to serotonin receptors? Molecular Brain 7, 49. https://doi.org/10.1186/s13041-014-0049-y.

Goodwin, G. M., Holmes, E. A., Andersson, E., Browning, M., Jones, A., Lass-Hennemann, J., ... \& Visser, R. M. (2018). From neuroscience to evidence based psychological treatments
-The promise and the challenge. ECNP March 2016, Nice, France. European College of Neuropsychopharmacology 28(2), 317-333. https://doi.org/10.1016/j.euroneuro.2017.10.036.

Gray, J. A. (1987). The Neuropsychology of Anxiety. Oxford University Press: Oxford, UK.

Groenewegen, H. J., \& Uylings, H. B. M. (2000). The prefrontal cortex and the integration of sensory, limbic and autonomic information. Progress in Brain Research 126, 3-28.

Halberstadt, A. L., van der Zee, J., Chatha, M., Geyer, M. A., \& Powell, S. B. (2019). Chronic treatment with a metabotropic mGlu2/3 receptor agonist diminishes behavioral response to a phenethylamine hallucinogen. Psychopharmacology 236(2), 821-830. https://doi.org/10.1007/s00213-018-5118-y.

Hannigan, B., Simpson, A., Coffey, M., Barlow, S., \& Jones, A. (2018). Care Coordination as Imagined, Care Coordination as Done: Findings from a Cross-national Mental Health Systems Study. International Journal of Integrated Care 18(3), 12. https://doi.org/10.5334/ijic.3978.

Hedges, D. W., Massari, C., Salyer, D. L., Lund, T. D., Hellewell, J. L., Johnson, A. C., \& Lephart, E. D. (2003). Duration of transcranial magnetic stimulation effects on the neuroendocrine stress response and coping behavior of adult male rats. Progress in Neuro-Psychopharmacology \& Biological Psychiatry 27(4), 633-638. https://doi.org/10.1016/S02785846(03)00052-6.

Heyes, C., \& Dickinson, A. (1990). The intentionality of animal action. Mind and Language 5, 87-104.

Hindmarch, I. (2001). Expanding the horizons of depression: beyond themonoaminehypothesis. Human Psychopharmacology 16(3), 203-18. https://doi.org/10.1002/hup.288.

Hnasko, T. S., \& Edwards, R. H. (2012). Neurotransmitter Corelease: Mechanism and Physiological Role. Annual Review of Physiology 74, 225-243.

Høifødt, R. S., Lillevoll, K. R., Griffiths, K. M., Wilsgaard, T., Eisemann, M., Waterloo, K., \& Kolstrup, N. (2013). The clinical effectiveness of web-based cognitive behavioral therapy with face-to-face therapist support for depressed primary care patients: randomized controlled trial. Journal of Medical Internet Research 15(8), e153. https://doi.org/10.2196/ jmir.2714.

Hollon, S. D., Jarrett, R. B., Nierenberg, A. A., Thase, M. E., Trivedi, M., \& Rush, A. J. (2005). Psychotherapy and medication in the treatment of adult and geriatric depression: which monotherapy or combined treatment? Journal of Clinical Psychiatry 66, 455-468.

Holmes, E. A., Ghaderi, A., Harmer, C. J., Ramchandani, P. G., Cuijpers, P., Morrison, A. P., ... \& Craske, M. G. (2018). The Lancet Psychiatry Commission on psychological treatments research in tomorrow's science. Lancet Psychiatry 5; 3, 237286. https://doi.org/10.1016/S2215-0366(17)30513-8.

Honeyman, J. F. (2016). Psychoneuroimmunology and the Skin. Acta Dermato-Venereologica 96(217), 38-46. doi 10.2340/ 00015555-2376.

Hunyady, L., Vauquelin, G., \& Vanderheyden, P. (2003). Agonist induction and conformational selection during activation of a G-protein-coupled receptor. Trends in Pharmacological Sciences 24(2), 81-86. https://doi.org/10.1016/S0165-6147 (02)00050-0. 
Hurley, K. M., Herbert, H., Moga, M. M., \& Saper, C. B. (1991). Efferent projections of the infralimbic cortex of the rat. Journal of Comparative Neurology 308, 249-276. https://doi. org/10.1002/cne.903080210.

Iida, T., Yoshikama, T., Kárpáti, A., Matsuzawa, T., Kitano, H., Mogi, A., ... \& Yanai, K. (2017). JNJ1081457, a histamine H3 receptor inverse agonist, regulates in vivo microglial functions and improves depression-like behaviours in mice. Biochemical and Biophysical Research Communications 488(3), 534-540. https://doi.org/10.1016/j.bbrc.2017.05.081. Epub 2017 May 16.

Jin, L. Q., Wang, H. Y., \& Friedman, E. (2001). Stimulated D1 dopamine receptors couple to multiple $\mathrm{G}$ proteins in different brain regions. Journal of Neurochemistry 78, 981-990.

Joca, S. R., Moreira, F. A., \& Wegener, G. (2015). Atypical Neurotransmitters and the Neurobiology of Depression. CNS \& Neurological Disorders - Drug Targets 14(8), 1001-1011. https://doi.org/10.2174/1871527314666150909114804.

Kalsi, N., Altavilla, D., Tambelli, R., Aceto, P., Trentini, C., Di Giorgio, C., \& Lai, C. (2017) Psychotherapy Compared to Antidepressant Therapy in Anxiety and Depression Disorders: A Meta-Analysis. Frontiers in Psychology, 07. https://doi. org/10.3389/fpsyg.2017.00927.

Kappelmann, N., Rein, M., Fietz, J., Mayberg, H. S., Craighead, W. E., Dunlop, B. W., ... \& Kopf-Beck, J. (2020). Psychotherapy or medication for depression? Using individual symptom meta-analyses to derive a Symptom-Oriented Therapy (SOrT) metric for a personalised psychiatry. BMC medicine, 18, 1-18. https://doi.org/10.1186/s12916-020-01623-9.

Karlsson, H., Hirvonen, J., Kajander, J., Markkula, J., RasiHakala, H., Salminen, J. K., ... \& Hietala, J. (2010). Research letter: psychotherapy increases brain serotonin 5-HT 1A receptors in patients with major depressive disorder. Psychological Medicine 40, 523-528. https://doi.org/10.1017/ S0033291709991607.

Kenakin, T. (2002). Efficacy at G-protein-coupled receptors. Nature Reviews Drug Discovery 11, 103-110. https://doi. org/10.1038/nrd722.

Kennedy, S. H., Konarski, J. Z., Segal, Z. V., Lau, M. A., Bieling, P. J., McIntyre, R. S., \& Mayberg, H. S. (2007). Differences in brain glucose metabolism between responders to $\mathrm{CBT}$ and venlafaxine in a 16-week randomized controlled trial. American Journal of Psychiatry 164(5), 778-788. https://doi. org/10.1176/ajp.2007.164.5.778.

Kumar, A., Rinwa, P., Kaur, G., \& Machawal, L. (2013). Stress: Neurobiology, consequences and management. Journal of Pharmacy and Bioallied Sciences 5(2), 91-97. https://doi. org/10.4103/0975-7406.111818.

Lambert, M. J. (2005). Early response in psychotherapy: further evidence for the importance of common factors rather than «placebo effects». Journal of Clinical Psychology 61(7), 855869. https://doi.org/10.1002/jclp.20130.

The Lancet (2018). GBD 2017: a fragile world. Lancet 392, 10159:1683. https://doi.org/10.1016/S0140-6736(18)32858-7.

Licinio, J., \& Wong, M. (2020) Advances in depression research: second special issue, 2020, with highlights on biological mechanisms, clinical features, co-morbidity, genetics, imaging, and treatment. Molecular Psychiatry 25, 1356-1360. https://doi.org/10.1038/s41380-020-0798-1.
Linden, D. E. J. (2006). How psychotherapy changes the brain - the contribution of functional neuroimaging. Molecular Psychiatry 11, 528-538. https://doi.org/10.1038/sj.mp.4001816.

Liu, M., Fitzgibbon, M., Wang, Y., Reilly, J., Qian, X., O’Brien, T., ... \& Roche, M. (2018). Ulk4 regulates GABAergic signaling and anxiety-related behavior. Translational Psychiatry 8(1), 43. https://doi.org/10.1038/s41398-017-0091-5.

Maggio, R., Vogel, Z., \& Wess, J. (1993). Coexpression studies with mutant muscarinic/adrenergic receptors provide evidence for intermolecular «cross-talk» between G-protein linked receptors. Proceedings of the National Academy of Sciiences U.S.A. 90, 3103-3107.

Marwood, L., Wise, T., Perkins, A. M., \& Cleare, A. J. (2018). Meta-analyses of the neural mechanisms and predictors of response to psychotherapy in depression and anxiety. Neuroscience \& Biobehavioral Reviews 95, 61-72. https://doi. org/10.1016/j.neubiorev.2018.09.022.

McKell-Carter, R., Hofstötter, C., Tsuchiya, N., \& Koch, C. (2003). Working memory and fear conditioning. Proceedings of the National Academy of Sciences U.S.A 100, 1399-1404. https://doi.org/10.1073/pnas.0334049100.

Merighi, A. (2018). Costorage of High Molecular Weight Neurotransmitters in Large Dense Core Vesicles of Mammalian Neurons. Frontiers in Cellular Neuroscience 12, 272. Published online 2018 Aug 21. https://doi.org/10.3389/fncel.2018.00272.

Messina, I., Sambin, M., Palmieri, A., \& Viviani, R. (2013). Neural correlates of psychotherapy in anxiety and depression: a meta-analysis. Plos ONE 8:e74657. https://doi.org/10.1371/ journal.pone.0074657.

Millan, M. J. (2003). The neurobiology and control of anxious states. Progress in Neurobiology 70(2), 83-244.

Millan, M. J., Gobert, A., Audinot, V., Dekeyne, A., \& NewmanTancredi, A. (1999). Inverse agonists and serotonergic transmission: from recombinant, human serotonin (5HT)1B receptors to G-protein coupling and function in corticolimbic structures in vivo. Neuropsychopharmacology 21, 61S-67S. https://doi.org/10.1016/S0893-133X(99)00007-X.

Mishra, B. R., Sarkar, S., Praharaj, S. K., Mehta, V. S., Diwedi, S., \& Nizamie, S. H. (2011). Repetitive transcranial magnetic stimulation in psychiatry. Annals of Indian Academy of Neurology 14(4), 245-251. https://doi.org/10.4103/09722327.91935.

Moncrieff, J. (2016) Misrepresenting harms in antidepressant trials. British Medical Journal 352:i217. https://doi. org/10.1136/bmj.i217.

Moriana, J. A., \& Martínez, V. A. (2011) La psicología basada en la evidencia y el diseño y evaluación de tratamientos psicológicos eficaces.Revista de Psicopatología y Psicología Clínica 16 (2), 81-100.

Müller, V. I., Cieslik, E. C., Serbanescu, I., Laird, A. R., Fox, P. T., \& Eickhoff, S. B. (2017). Altered Brain Activity in Unipolar Depression Revisited: Meta-analyses of Neuroimaging Studies. JAMA Psychiatry 74(1), 47-55. https://doi. org/10.1001/jamapsychiatry.2016.2783.

Nasrallah, H. A. (2006). Medications with psychotherapy: A synergy to heal the brain. Current Psychiatry 5(10):11-12.

Niemeier, V., Kupfer, J., Al-Abesie, S., Schill, W. B., \& Gieler, U. (1999). From neuropeptides and cytokines to psychotherapy. Skin diseases between psychoneuroimmunology research and 
psychosomatic treatment. Forschende Komplementärmedizin 6 Suppl 2, 14-18. https://doi.org/10.1159/000057141.

Pan, Y. X., Bolan, E., \& Pasternak, G. W. (2002). Dimerization of morphine and orphaninFQ/nociceptin receptors: generation of a novel opioid receptor subtype. Biochemical and Biophysical Research Communications 297, 659-663.

Panksepp, J. (1993). Neurochemical control of moods and emotions: Amino acids to neuropeptides. In The handbook of emotions (ed. M. Lewis and J. Haviland), pp. 87-107. Guilford

Panksepp, J. (2003). At the interface of the affective, behavioral, and cognitive neurosciences: Decoding the emotional feelings of the brain. Brain and Cognition 52, 4-14.

Panksepp, J. (2010). Affective neuroscience of the emotional BrainMind: evolutionary perspectives and implications for understanding depression. Dialogues in Clinical Neuroscience 12(4): 533-545.

Petersen, T. J. (2006). Enhancing the efficacy of antidepressants with psychotherapy. Journal of Psychopharmacology $20(3$ Suppl), 19-28. doi :10.1177/1359786806064314.

Pralong, E., Magistretti, P., \& Stoop, R. (2002). Cellular perspectives on the glutamate-monoamine interactions in limbic lobe structures and their relevance for some psychiatric disorders. Progress in Neurobiology 67, 173-202.

Ressler, K. J., \& Nemeroff, C. B. (2000). Role of serotonergic and noradrenergic systems in the pathophysiology of depression and anxiety disorders. Depression and Anxiety 12(Suppl 1), 2-19.https://doi.org/10.1002/1520-6394(2000)12:1+<2::AIDDA2>3.0.CO;2-4.

Roiser, J. (2015). What has neuroscience ever done for us? Psychologist, 28, 284-287.

Sandín, B., Chorot, P., y Valiente, R.M. (2012). Transdiagnóstico: Nueva frontera en psicología clínica. Revista de Psicopatología y Psicología Clínica, 17, 185-203. doi: https://doi.org/10.5944/ rppc.vol.17.num.3.2012.11839.

Searle, J.R. (1983). Intentionality: An essay in the philosophy of mind. Cambridge University Press

Seeberg, I., Kjaerstad, H. L., \& Miskowiak, K. W. (2018). Neural and Behavioral Predictors of Treatment Efficacy on Mood Symptoms and Cognition in Mood Disorders: A Systematic Review. Frontiers in Psychiatry 9, 337. https://doi. org/10.3389/fpsyt.2018.00337. eCollection 2018.

Seifert, R., \& Wenzel-Seifert, D. (2002). Constitutive activity of G-protein-coupled receptors: cause of disease and common property of wild-type receptors. Naunyn-Schmiedeberg's Archives of Pharmacology 366, 381-416. https://doi.org/10. 1007/s00210-002-0588-0.

Sharpley, C. F., \& Bitsika, V. (2013). Differences in neurobiological pathways of four «clinical content» subtypes of depression.
Behavioural Brain Research 256, 368-376. https://doi. org/10.1016/j.bbr.2013.08.030.

Teng, S., Guo, Z., Peng, H., Xing, G., Chen, H., He, B., ... \& Mu, Q. (2017). High-frequency repetitive transcranial magnetic stimulation over the left DLPFC for major depression: Sessiondependent efficacy: A meta-analysis. European Psychiatry 41, 75-84. https://doi.org/10.1016/j.eurpsy.2016.11.002.

Thase, M. E., Wright, J. H., Eells, T. D., Barrett, M. S., Wisniewski, S. R., Balasubramani, G. K., ... \& Brown, G. K. (2018). Improving the Efficiency of Psychotherapy for Depression: Computer-Assisted Versus Standard CBT. American Journal of Psychiatry 175(3), 242-250. https://doi.org/10.1176/appi. ajp.2017.17010089.

Thompson, F., \& Craighead, M. (2008). Innovative approaches for the treatment of depression: Targeting the HPA Axis. Neurochemistry Research 33, 691-707. https://doi.org/10. 1007/s11064-007-9518-3.

Trivedi, M. H., Fava, M., Wisniewski, S. R., Thase, M. E., Quitkin, F., Warden, D., ... \& Rush, A. J. (2006) Medication augmentation after the failure of SSRIs for depression. New England Journal of Medicine 354:1243-1252. https://doi. org/10.1056/NEJMoa052964.

Van der Pompe, G., Antoni, M. H., Duivevoorden, H. J., de Graeff, A., Simonis, R. F., van der Vegt, S. G., \& Heijnen, C. J. (2001). An exploratory study into the effect of group psychotherapy on cardiovascular and immunoreactivity to acute stress in breast cancer patients. Psychotherapy and Psychosomatics 70(6), 307-318. https://doi.org/10.1159/000056271.

Wilkinson, S. T., Holtzheimer, P. E., Gao, S., Kirwin, D. S., \& Price, R. B. (2019). Leveraging Neuroplasticity to Enhance Adaptive Learning: The Potential for Synergistic SomaticBehavioral Treatment Combinations to Improve Clinical Outcomes in Depression. Biological Psychiatry 85(6), 454465. https://doi.org/10.1016/j.biopsych.2018.09.004.

Willner, P., Scheel-Krüger, J., \& Belzung, C. (2013). The neurobiology of depression and antidepressant action. Neuroscience \& Biobehavioral Reviews 37(10 Pt 1), 23312371. https://doi.org/10.1016/j.neubiorev.2012.12.007.

Wischhof, L., \& Koch, M. (2016). 5-HT2A and mGlu2/3 receptor interactions: on their relevance to cognitive function and psychosis. Behavioural Pharmacology 27(1), 1-11. https:// doi.org/10.1097/FBP.0000000000000183.

Zeng, J., Kitayama, I., Yoshizato, H., Zhang, K., \& Okazaki, Y. (2003). Increased expression of corticotropin-releasing factor receptor mRNA in the locus coeruleus of stress-induced rat model of depression. Life Sciences 73(9), 1131-1139. https:// doi.org/10.1016/s0024-3205(03)00417-x. 
